To the Editors:

\title{
Labels, packages and leaflets in drugs and devices: the language matters a lot
}

The information given to the public on drugs, cosmetics and devices is governed by the Cosmetics, Devices and Drugs Act of 1980. The regulations do not mention the language to be used in providing such information (1). We did a study with two objectives: to estimate frequency of using Sinhala, Tamil and English in labelling and in the product information leaflets (PIL) of commonly sold drugs and devices, and to identify ability of patients to read English names of drugs.

SM visited a purposive sample of 35 pharmacies around Colombo and collected data using a questionnairebased interview. Two lists of frequently sold preparations were developed as follows.

1. The names of 5 drugs and 5 over-the-counter preparations (OTC) with the most rapid turnover in each pharmacy.

2. A list of commonest selling trade preparations for 24 categories of drugs (eg. anti-hypertensives, anti-epileptics), 7 categories of OTC (eg. vitamin syrups) and 5 categories of devices (eg.inhalers).

The languages used in the packaging, boxes, bottles and PIL of the listed preparations were noted.

Ability to read English terms was assessed in a randomly selected sample of 40 clinic patients and 50 in-patients of the University Medical Unit. They were requested to read a list of 50 commonly selling drugs and their most popular trade name, typed in English. A simple score was given on the number correctly named.

Information was available from 120 trade preparations (of 60 individual drugs), 32 OTC preparations and 14 devices. Of the latter the clinically relevant devices were in 2 categories (inhalers for asthma [n=7] and suppositories $[n=2]$. Results are summarised in the Table.

Twenty seven out-patients $(65 \%)$ and $27(54 \%)$ in-patients were not able to read a single English name from the list of drugs.
Table

$\begin{array}{lll}\text { Foils or } & \text { Product insert } & \text { Product insert } \\ \text { labelling in } & \text { information } & \text { information } \\ \text { Sinhala or } & \text { leaflets } & \text { leaflets } \\ \text { Tamil } & \text { available } & \begin{array}{l}\text { containing } \\ \text { Sinhala or } \\ \end{array} \\ & & \text { Tamil }\end{array}$

$\begin{array}{lll}\text { Prescription } & 0 & 78(65 \%)\end{array}$

drug $(n=120)$

OTC $(n=31) \quad 5(16.1 \%) \quad 20(64.5 \%) \quad 6(19.4 \%$

Devices $(n=14) \quad 0 \quad 14(100 \%) \quad 2(14.3 \%)$

Information on drugs and devices are available mainly in English. A majority of drugs did not contain even a label in Sinhala or Tamil, and more than $50 \%$ of our patients were unable to read the English name of any of the drugs. Therefore, an appreciable proportion of our patients is likely to remain ignorant of the information related to their medications. Considering the poor level of English at a national level ( $75 \%$ of 15 to 29 year olds are not able to read English satisfactorily), the proportion of consumers so affected is probably high (2).

Urgent steps are necessary to ensure that Sinhala and Tamil are used on labels and PIL. The absence of information in the national languages discriminates against a majority of our citizens. Until this is rectified, the efforts of the medical community to impart health education regarding drugs are likely to have a limited impact.

\section{References}

1. The Gazette of the Democratic Socialist Republic of Sri Lanka. Extraordinary 378/3, 2 December 1985, Government notifications: Cosmetics, Devices and Drugs Act No 27 of 1980 amended by Act No 380 of 1984 .

2. National Youth Survey: Overview report, Sri Lanka 2000, University of Colombo.

Shirmila Mendis, Medical Officer, Regional Director's Office, Gampaha District and Saroj Jayasinghe, Associate Professor, Department of Clinical Medicine, Faculty of Medicine, University of Colombo. (Competing interest: On occasion SJ has evaluated drugs for the Drug Regulatory Authority of the Ministry of Health. Correspondence, SJ, telephone: +94 1 695300). 